\title{
Understanding the Science of Other Cultures
}

by

Paul T. Keyser

New York, NY

paul.t.keyser.dr.dr@gmail.com 


\begin{abstract}
A discussion of Science in the Forest, Science in the Past edited by Geoffrey Lloyd and Aparecida Vilaça.

About the Author

PAUL T. KeYSER studied physics and classics at Duke University and at the University of Colorado at Boulder, where he earned doctorates in physics and in classics. After some years of research and teaching in classics at the University of Alberta (Edmonton), Cornell University, the Center for Hellenic Studies (Washington DC), and other places, he returned to his first love, programming. He worked as a software engineer at the IBM Watson Research Center, then at Google, Climate, and Bridgewater. He is currently a software engineer at Relativity. His publications include work on gravitational physics, stylometry, and ancient science and technology. He is co-inventor on some patents in computer science. Three co-edited books have appeared: Greek Science of the Hellenistic Era: A Sourcebook, Encyclopedia of Ancient Natural Scientists, and Oxford Handbook of Science and Medicine in the Classical World. Moreover, he has published a monograph, Recovering a Late-Antique Edition of Pliny's Natural History. Current projects include papers on ancient mechanics and on Plato's astronomy, as well as books on the evolution of ancient science and on "classic" lineages.
\end{abstract}




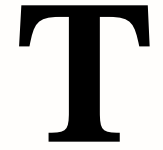

hose whose occupation it is to study histories of sciences begin, like Aristotle, with wonder: "What could they mean by that?" Some of those studies consider the sciences of people from long ago, whereas others consider the sciences of more recent people but from cultures different from those of the student. Participants in such efforts mostly know to expect a conceptual chasm and yet hope to cross it. Moreover, even when studying sciences within one's home culture, there are arresting moments of defamiliarization and dizzying chasms open before our footsteps. ${ }^{1}$ Conversely, philosophers and theologians have often made hegemonic claims for their approach, arrogating titles such as "Queen of the Sciences". What then to say when a diverse tribe of scholars sets out to explore "Science in the Forest, Science in the Past", as presented in a special issue of $H A U$ [Lloyd and Vilaça 2019]?

First, a little context. Some early Greek scientists eagerly explored the conceptual worlds of the "alien" cultures to which they had some access; Babylonians, Egyptians, Indians, Persians, and Scythians are attested as informants or teachers. ("Alien" of course cuts both ways, as Xenophanes famously remarked [Diels and Kranz 1951, frr. 21B15-16], speaking about how foreigners depict the gods - that is, like themselves.) No doubt, the attempts of those Greeks to explore (or exploit) the scientific ideas of those neighbors would not pass muster in a contemporary department of anthropology. But the activity attests to a human belief that other peoples' ideas may be commensurate with, and even relevant to, our own concerns. The Romans went further, of course, and besides the fascination many of them felt for Celtic, Etruscan, or Punic wisdom, there was a broad-based "translation movement" that rendered Greek science, or some parts of it at least, accessible in Latin to interested readers [Keyser 2010].

Travelers may import new ideas and ways of thinking, easing the task of an anthropologist of science, but narrowing any results to what the travelers happen to import. Such down-the-line trade has long been a feature of human cross-cultural interaction, and allows for a good deal of assimilation and transformation. The remark by Francis Bacon-that the greatest

1 E.g., Kidder 1981 and Traweek 1988. 
modern inventions are printing, gunpowder, and the magnetic compass, but no-one knows their origin-exemplifies that sort of assimilation and transformation [Bacon 1620, 147-148: cf. Boruchoff 2012, esp. 138]. It also amuses, if only because we know that all of them came west from China. ${ }^{2}$ The long and rich interaction between the scientific cultures of the Islamic caliphates and those of the Latin west displays another kind of trade in ideas and sciences. Translation was essential to that set of enterprises, starting with the translations of Greek scientific literature into Syriac and Arabic in the eighth century AD, but including also the numerous later renderings of Arabic and Greek texts into Latin.

So we find ourselves immersed in a long-running stream of cultural interaction around science. That stream as I have described it embodies an activity that assumes the possibility of translation and communication. Moreover, it is a "mercantile" style of interaction, in which all parties extract from the sciences of the respectively "alien" culture(s) mostly what they themselves expect to be "useful" for their own interests. That limits the degree to which "alien" science can be understood because technologies are more fungible than ideas. ${ }^{3}$

The idea that understanding the science (or poetry) of an "alien" culture might be of interest and worthwhile for its own sake is radical and rare in human history, as it seems. When the Romans or the Arabs translated Greek science, it seems that they expected to learn something useful about the world. In either case, it is debatable to what extent the dominant culture believed that Greek literature or culture was of value per se. ${ }^{4}$ Romans were certainly fascinated by Greek culture and some Romans at least felt that that their conquest of the Greek world had enriched the Roman world by more than mere territory or Macht. ${ }^{5}$ Modern enterprises such as ethnobotany or

2 Perhaps we should add eyeglasses, which are first attested in the west around AD 1300? Laufer 1907 argues for a Chinese origin, but Rosen 1956 and Needham 1962, 118-122 reject this: see also Ilardi 2007, 3-50.

3 Medical anthropology is indeed highly pragmatic: Pfeiffer and Nichter 2008; Goodson and Vassar 2011; Joralemon 2017; and Singer, Baer, Long, and Pavlotski 2020.

4 The earlier case of Assyrians studying Sumerian literature might reflect a similar response. On this activity, see Oppenheim 1977, 16-24, 235-238, 249, 255-256; and Michalowski 2017, esp. 205-207.

5 Cicero describes Greeks as excelling Romans in all forms of literature [Tusc. 1.3], and Horace remarks that conquered Greece took Rome captive, thus bringing artes 
ethno-agriculture operate at least in part with a similar goal of (possibly mutual) benefit. ${ }^{6}$

None of that is anthropology, which I understand to be occupied with the study of "alien" cultures per se. That is, cultures become topics of study not because they might provide something useful, but because they are of intrinsic interest. (That distinction is not absolute: learning about another culture in an appreciative way will naturally lead to reflections and reconsiderations about one's own culture.) But that long history of cultural exchange, whether between neighbors as when Greek scientists reached out to Egypt or Mesopotamia, or between a conquered ("colonized") people and their new overlords, runs as an undercurrent beneath all our modern attempts to perform anthropology.

I am no anthropologist, but we hope that the silos of scholarship are not opaquely incommensurable. Moreover, I hold that it is best when there is "free trade" and open dialog between disciplines. (Classicists, historians of ancient science, and other students of ancient cultures may be seen as practicing a kind of time-traveling anthropology [cf. Holmes 2020].) Given that Geoffrey Lloyd was a leading participant within the flash-tribe that gathered at the conference to explore these questions, I think that readers can have confidence that some degree of communication was both a goal and an outcome. The scholars pursued various paths into the forest, but a chief discursive frame encompassed the issue of "ontologies". Some of the papers were more explicitly concerned with that frame. Others followed a path around mathematics. A third, smaller cluster of papers explores some aspects of artificial intelligences, or as I would prefer to label them, cyborgs. ${ }^{7}$

\section{Ontologies}

Although invoked as a guiding inquiry of the conference, the "clash of ontologies" did not deeply engage many of the participants, as Lloyd and Vilaça remark [179-180] in their closing essay. Nevertheless, the issue is latent in many of the papers and is worth exploring. One simple example

to Rome [Epist. 2.1.156-157]. Somewhat differently, Vergil [Aeneid 6.847-853] predicts that Rome shall excel in rule, let others excel in arts.

6 See Prance, Chadwick, and Marsh 1994; Minnis 2000; Soejarto, et al. 2005; and Voeks 2018.

7 Two papers in this volume fall outside these categories and definitely outside my expertise, so I will keep silent: Kuper, "Deconstructing Anthropology" [10-22] and Herzfeld, "What is a Polity?" [23-35]. 
of the problem would be the classification of animals, which for modern science involves distinctions between mammals, birds, and fish (among others). However, a more ecocentric ontology might exploit categories like "flying creatures" or "creatures dwelling in Air" (and thus bats, bees, and finches are close relatives) as well as "swimming creatures" or "creatures dwelling in Water" (and thus carp, dolphins, and shrimp are close relatives). So the two distinct ontologies, ecocentric and phylocentric, encode different concepts-but the ontologies are not incommensurable or incommunicable. Vilaça, in the contribution "Inventing Nature: Christianity and Science in Indigenous Amazonia" [44-57], addresses contrasting the ontologies of humans and animals of the Wari' and of modern science. For the Amazonian Wari', animals and humans share a great deal, whereas for some strands of European and Mediterranean thought, humans are radically distinct from animals. Likewise, there is a contrast between the meanings assigned to singularity and duality: for the Wari', singularity (the number one and related concepts) is lonely and incomplete, whereas duality (the number two and related concepts) is richer and more potent. That contrasts with a tradition in European thought (found among Pythagoreans, as well as Neoplatonists and monotheists) that "the One" is primal, original, and Good, whereas "the Dyad" is the opposite of those. But traditions in western, or even modern, sciences about the significance of numbers, or the relation of humans to animals, are themselves not unitary. Descartes' view that animals are simply bionic machines was never the only choice, and there is a rich array of debate and tradition in European and Mediterranean science and philosophy about the ontology of animals vis-à-vis humans [Sorabji 1993]. (Moreover, I would respectfully but strongly dissent from the claim that modern western science has "Christian foundations" or "is monotheist" [49]. Science hardly began with the 17th-century "Scientific Revolution", and several other contributions to these proceedings emphasize that point [see Lloyd, p. 37] and especially the contributions on mathematics, below.)

Translation, too, implicates ontologies, and necessarily so. Any translation is an assertion of semantic proximity, which in turn is an assumption of overlapping ontology. As Lloyd argues in "The Clash of Ontologies and the Problems of Translation and Mutual Intelligibility" [36-43], even such "simple" words as "fire" and "water" are slippery to translate. He is taking those as terms that are not "highly theory-laden" [38], but I think that his own discussion shows that they are actually theory-laden. He cites translations of those words among Chinese, English, and Greek—and at least in Greek and Chinese, the chosen example terms refer to fundamental "elements" or 
"phases" of matter. To translate ancient Greek « $\delta \omega \rho \rho$ (hydōr) or Chinese 《水》 (shul) into English “water" is both "obvious" and yet missing many res-

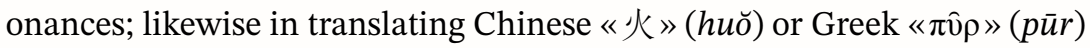
as "fire" [Lloyd 2012, 85-89]. Other "obvious" terms may be translated with no more-and no less—risk of ontological clash, such as "book" or "city," or even "food" or "school". Any effective translation will arrive accompanied by a host of adjutants, serving to qualify, nuance, or clarify.

Lloyd, as he has done elsewhere, takes an optimistic position on translation. He holds these claims to be foundational [36]: ${ }^{8}$

(1) no translation is ever perfect and complete, all are provisional and revisable; (2) there is indeed no perfect, complete, mutual understanding, even when all interlocutors share the same natural language. On the other hand, (3) some understanding is always possible, even across divergent systems, and even across incommensurable paradigms, even if (4) there is no neutral vocabulary in which it can be expressed. This depends (5) on allowing that the terms in any language exhibit what I call "semantic stretch".

As Lloyd goes on to argue [39, 41], there is no neutral or universal language in which to disambiguate terms and semantics; one just has to work it out tentatively and provisionally. He points out that "incommensurability" is not a threat, but is instead an opportunity [41]. I would go further, and claim that an apparent "incommensurability" is only provisional, and is always a sign that can elicit wonder and curiosity, and thus reflection, engagement, and exploration.

I offer an enlightening example from modern science of a semantic stretch that is also an issue of apparently clashing ontologies. Chemists often speak of chemical bonds [Pauling 1960] and the usual initial distinction is between the typical bond of "inorganic" chemistry and the "covalent" bond, as found in "organic" chemistry. The "ionic" bond is between two atoms, in which one or more electrons are entirely transferred from one atom to the other. The canonical example is salt, in which a single sodium atom yields an electron to a single chlorine atom. In simplistic contrast to this is the "covalent" bond, that is, in compounds of carbon, hydrogen, oxygen, and nitrogen (primarily). In the covalent bond, there is no wholesale transfer, and the atoms participating in a bond share one or more electrons. One simple example is water, in which each of two hydrogen atoms shares its electron

${ }^{8}$ Lloyd here reprises 1987, 172-214, esp. 174-181, citing Porzig 1934 as similar, and 208-214: cf. also Lloyd 2002, 123, where again Porzig 1934 is credited. 
with a single oxygen atom. (These terms originated in the 1930s, although the concepts were being explored 20 years prior.)

But in fact, the ontology is unstable, since the ionic or covalent character of a bond is a matter of degree, not dichotomy. Moreover, other types of bonds also exist, such as the "hydrogen bond", in which a hydrogen atom participates both in its canonical single covalent bond and in a weaker bond with a third atom that has some electrons on its surface that are not participating in any other bond. This bond-type is responsible for many of the remarkable properties of water. Further, compounds of boron and hydrogen (known as "boranes") display yet another type of bonding, in which the single electron of a hydrogen atom is shared among three atoms, namely, two boron atoms and the hydrogen atom itself. The complexities ramify, and there are, for example, "clathrates"-compounds in which a large molecule forms a "cage" in which a smaller molecule is bound. All of this shows how even within a single scientific discipline and in a single language, there is an instability, or at least complexity, of ontologies. That seems to chime well with Lloyd's advice [41] that investigators allow for the "multidimensionality of the explananda".

The essay by Jardine, "Turning to Ontology in Studies of Distant Sciences" [172-178], employs the useful covering term "distant science(s)" to refer alike to sciences of the past and to those of "alien" cultures. Jardine argues for a pluralist view of science(s), so that, in his example, "indigenous practices of pigment preparation" would cohere with western industrial lab chemistry. Indeed, many journals are devoted to understanding indigenous or ancient practices of pigment preparation, along with many other "chemical” techniques: e.g., Archaeometry (1958-). Such work exemplifies some aspects of the practice of translation, that is, of commensurability, for materials science(s), across cultures and time. The concluding remark [176] is well worth quoting:

For however deep the understanding we may achieve by "going native" in the forest or the past, we owe it to ourselves and our audiences to provide comprehensible interpretations.

Jardine calls it "the principle of responsibility," evoking a strong commitment to working hard to perceive the nature of the commensurability, and to translate that for readers.

9 Lloyd has very insightfully explored ontologies, and the issues of translation around them, in 2015, 88-108. 


\section{Mathematics}

Turning now to the papers that followed a path around mathematics, we have a contribution by de Almeida asking "Is There Mathematics in the Forest?" [86-98], plus three contributions on each of three literate cultures: Chinese, Greco-Roman, and Indian. Those three are, respectively, "Different Clusters of Text from Ancient China, Different Mathematical Ontologies" by Chemla [99-112]; "Mathematical Traditions in Ancient Greece and Rome" by Cuomo [75-85]; and "Shedding Light on Diverse Cultures of Mathematical Practices in South Asia" by Keller [113-125]. These contributions exist within a larger framework of "ethnomathematics", itself a problematic term, and an active set of fields. ${ }^{10}$ Those fields offer studies of mathematical notation in literate cultures [see Chrisomalis 2010], studies of mathematical practice in specific communities, ${ }^{11}$ and plenty of studies of learning styles. ${ }^{12}$

De Almeida argues for "the existence of universal mathematical capabilities," supported by evidence in the form of "recursive rules used to produce consistent patterns that are transportable across distinct domains of thought and action" [86]. Even without the restriction "recursive", that would be a proper definition of the work of mathematicians in any culture. Detecting recursion is a pleasant extra accomplishment, and not just because recursion is a concept of modern western mathematics that is widely used in writing computer code. It also foregrounds a fundamental human capacity, visible also in the structures of human language. The primary and extended example concerns how kin relations can encode abstract maths, among the Cashinahua (better, "Huni Kuin") of Acre state in western Brazil and nearby Peru [90-93]. As de Almeida convincingly demonstrates, kinship structure encodes formal mathematical statements, such as multiplicative identity ( $f * e=f=e * f$, with "e" the identity element for the operation "*", and " $\mathrm{f}$ " any element of the set over which the operation is defined). This encoding represents the rules for combining kinship terms, such as epa $*$ bets $a=e p a$ (translated as "same-sex parent * same-sex sibling = same-sex parent"). The vocabulary and grammar of the kinship system also encodes the self-inverse property $(f * f=e)$, as well as others.

10 See especially Barton 1996, Vithal and Skovsmose 1997, and Rivera and Rossi Becker 2008.

11 Many such, e.g., Millroy 1991 and Chahine and Naresh 2013.

${ }^{12}$ Widely cited is Eisenhart 1988. 
To demonstrate further that cross-paradigm translations are possible [93-94], de Almeida provides a translation involving irrational roots (of 2, 3, and 6) across the chasm between Euclid and Dedekind. ${ }^{13}$ De Almeida shows how the proof is valid both in Euclid's paradigm of irrational values and in Dedekind's paradigm for thinking irrational numbers (the "Dedekind cut", which defines an irrational number as the limiting boundary between a pair of disjoint sets of rational numbers). Another, more briefly drawn translation involves Euclid, Elem. 9.20, which proves that, given any list of prime numbers, there exists a prime not on the list, and thus that the set of primes is unbounded. As de Almeida says, we must pay close attention to what Euclid does, and does not, argue; and because of Euclid's careful language, the argument takes the same form, even after a paradigm shift in the theory of infinity, because it does not implicate any specific theory of infinity [94]. Another point also requiring careful attention is that the proof asserts that the number composed by adding 1 to the product of the primes in the list is either prime or else has a prime factor that is not in the list. To see that 1 plus the product of the primes in the list need not be prime itself, start with a list of the primes 3 and 5 , and find that $(3 \times 5)+1=16$, where 16 has a prime factor not on the list, namely, 2. Likewise, starting with the first six primes, namely $2,3,5,7,11$, and 13, one finds that 30,031 has the prime factors 59 and 509, not in the initial list.

Chemla's contribution on Chinese culture considers school texts of the 7 th century $\mathrm{AD}$, and tomb texts from "last centuries $\mathrm{BC}$ " - the two clusters "testify to two different ways of practicing mathematics, which related to different material practices" [99]. As Chemla says, using actor-created corpora is a better way to investigate ontologies in that it is both more principled and more effective. Such corpora reflect their underlying ontology in their technical language and material practices [100]. Chemla shows in detail that texts in the later cluster all regularly use rods for computing that are laid out on a surface in decimal place-value arrangements [100-109]; this is explicit in the Mathematical Canon by Master Sun, and implicit in other texts of the same later corpus. ${ }^{14}$ In contrast, the algorithms described in two tomb scrolls from $c a 200 \pm 15 \mathrm{BC}$, as well as some Qin-era texts in Beijing, also use rod-numerals; but they do not describe the operations of division

13 Here, de Almeida follows Stillwell 2016, 156-157.

14 The contribution here relies upon the valuable work of Chemla 2013 and Volkov 2014. 
and extracting roots in words that reflect the same ontology as in the commentaries [109-110]. Instead, the earlier mathematical texts "seem to reflect the use of operations as means to reach a result rather than as processes to be pondered" [109].

Cuomo's contribution on Greco-Roman culture considers the tradition(s) of Greek mathematics: the "theoretical" tradition and the allegedly contrasting "practical" tradition. The distinction is ancient and starts, as Cuomo demonstrates, with Plato and other authors. The "theoretical" tradition is mathematics as conceived by Plato, or as practiced in the pages of Euclid's Elements; the "practical" tradition is mathematics as seen in the corpus of Heron of Alexandria (mid-first-century AD). Cuomo views the dichotomy as unstable and shows how practices migrated across the very permeable boundary, and how modern attempts to maintain the distinction founder [75-81]. Instead, an approach using "situation-specificity, or situated learning" is to be preferred, along with "code-switching" [81]. That is, any given mathematician might produce more theoretical work in one situation and more practical work in another. Likewise, the language of a Greek (or any) mathematical work might vary between "theoretical" and "practical" depending on the intended audience or expected use of the work.

Moreover, Cuomo argues, an analysis of mathematical behavior in terms of situations is more responsive to details of the work and opens up more avenues for comparison, since similar situations might arise in quite distinct times and places. I would point out that the Archimedean corpus contains both "theoretical" works (such as Spiral Lines or Sphere and Cylinder) as well as "practical" efforts (such as Division of the Circle). Nor do the Cattle Problem or the Stomachion (however interpreted) easily fit into some binary classification. Likewise for Eratosthenes, both the "mean-obtainer" (mesolabon, a kind of slide-rule for extracting roots) and the Geography seem "practical" (or at least not "theoretical"); whereas the attested but lost work On Means would likely have been "theoretical".

Keller's contribution on Indian culture considers two contrasting practices of numbers, measures, and computations in South India [113]. One is documented in early Sanskrit mathematical treatises and commentaries (of the 7 th to 12 th centuries), the other in elementary mathematical educational texts in Tamil (of the 17th to 2oth centuries). The Sanskrit mathematical texts present abstract mathematics, in which calculations are performed on "pure" (unitless) numbers, and decimal place-value numerals are used 
[115-116]. The Sanskrit texts also present themselves as delineating a timeless discipline; that is, any given text claims to be "the reframing of a preceding treatise or of an orally transmitted doctrine" [115]. In contrast, the Tamil texts use Tamil numerals, which are decimal and non-positional, and the computations are made with units attached to the numbers [115-116]. Keller's analysis focuses on two common kinds of computations found in both sorts of texts:

(1) computations of areas [116-120], and

(2) computations of gold fineness [120-121].

As Keller shows, the two corpora are not utterly distinct, and some specific problems or methods appear in both [122].

All three of these contributions on literate cultures conclude, analogously, that the allegedly distinct or dichotomous corpora are not in fact separated by an incommensurable chasm. Greek "theoretical" and "practical" mathematics, Chinese Tang-dynasty school-texts, and Qin- or Han-dynasty tomb-texts, as well as Indian Sanskrit texts and Tamil texts, all show communication across the chasms.

\section{Cyborgs}

Turning finally to the (small) cluster of papers that explore some aspects of artificial intelligences, we have Blackwell, "Objective Functions: (In)humanity and Inequity in Artificial Intelligence" [137-146], and McCarty, "Modeling, Ontology and Wild Thought: Toward an Anthropology of the Artificially Intelligent" [147-161]. In both cases, I think that the full perspective here is better described using the word "cyborg". The artificial intelligences are considered under the same defamiliarized perspective as are the "distant" cultures of ancient China or contemporary Amazonia (to borrow the term from Jardine, as above). That is, the artificial intelligences are imagined as members of some "alien" culture that to be sure bears a rather special dependent relation to modern western culture but is nonetheless imagined as distinct or on the far side of a chasm. To express that uncanny relation, I want to use the word "cyborg".

Blackwell focuses on "the subjectivities embedded in these mechanical systems, and the human satisfactions and ambitions in constructing them" [137]. Two different approaches to those subjectivities are made. The first is to examine, briefly, the perhaps surprising procreative aspect of cyborgs [138]. Blackwell writes that the artificial construction of simulated humans in fiction seems often to become powerfully gendered, perhaps alluding to 
the gendered nature of all human procreation. The figure of the AI engineer building sexy robots and falling in love with them has many fictional precursors, including that of Pygmalion. Indeed the Turing Test itself was first posed as an Imitation Game in which the challenge assigned was not for a computer to imitate a man but for a man to imitate a woman.

Blackwell sharpens the point by suggesting that such creations "often" result in some excess and some retribution, as if such involvements transgress some well-defined moral order. Certainly some cyborg fictions have such an element, and perhaps the transgression is that the creator mates with (usually) his creation, thus violating the taboo against incest. (Indeed, here the use of the word "cyborg" enables sharper focus on the problem.)

But I do not think that the (surely fictional) "singularity" is either inherently retributive or necessarily sexual. It certainly smacks of the divine to hypothesize that some being(s) would gain such extreme, even infinite, power. The imagined "singularity" is an overly-simplified extrapolation of current trends, without any physical model to explain or validate the specific direction or degree of extrapolation. Even without an actual infinity, we may imagine a growth of cyborg power to an unpleasant or risky degree-just as one might extrapolate (on well-grounded assumptions) three more familiar catastrophes: nuclear, biological, or climatic. On the one hand, nation-states or others might increase the number and power of nuclear weapons and thus run the risk of an extremely destructive war. Or, new kinds of zoonoses, whether natural or artificial, might increase in number and fatality rate, until some apocalyptic plague breaks out. Or, thirdly, the degree of global warming might increase to such an extent that the structures of modern global society would crumble. But such extrapolations are at least founded on scientific measurements and experiments, which thus provide means of analysis and form a basis for attempting to evade hypothesized bad outcomes.

Blackwell also engages in a second line of investigation about subjectivities by examining the language used to describe certain aspects of the making of cyborgs [139-144]. Here he addresses three specific phrases or labels:

(1) "objective function",

(2) "logistic regression", and

(3) "oracles" and "ground truth" (two terms that regularly travel together).

The terminology is not usually used by practitioners in an ambiguous way, but, indeed, as Blackwell says [141], many computer scientists are poorly trained in basic principles of epistemology, while many philosophers are 
poorly trained in basic principles of engineering, meaning that they happily talk at cross-purposes with the aid of ambiguous terminology that neither properly understands.

So there is the potential for the perception of an incommensurability or clash of ontology. An "objective function" is a kind of component of many pieces of software, and would likely be used to create any eventual cyborg [139-140, 142-144]. As Blackwell says, one example is the objective function that evaluates the relative goodness of search results from any search engine (whether Google, Bing, or DuckDuckGo). Such a function is a mathematical transformation that defines how closely a given measurable result (of a computation) adheres to some defined goal. The "objective" in the phrase is, as Blackwell says, the goal being sought; so an "objective function" might better and more clearly be called a "goal-function". It is unfortunate that, by the usual ambiguity of language, an "objective" function can seem to refer to something that is "objective", i.e., in contrast to something "subjective". So here the actual issue of cyborg subjectivity concerns the goal-functions used to program the eventual cyborg, which were of course developed by the programmers who presumably used their subjective best estimates of what would work well in addition to whatever evidence they accumulated by testing proposed goal-functions.

The second label, "logistic regression", refers to a mathematical procedure that fits data to a "yes / no" model, or indeed to any categorical model [140-141]. That is, in trying to evaluate data to see if, for example, the data are more consistent with one outcome (from a list of distinct outcomes) than with other outcomes (on the same list), this procedure is used. It is not perhaps a well-named procedure, but it is widely used in data-analysis. The procedure is not very specific to the creation of cyborgs but would likely be used to program some of their behavior. Again, the actual issue of cyborg subjectivity concerns the lists of distinct outcomes used to define any logistic regressions in the eventual cyborg, which were of course developed by the programmers who presumably used their subjective best estimates of what would work well in addition to whatever evidence they accumulated by testing proposed outcome-lists. (It is something of a red herring to suggest that logistic regression is tainted by its origin in eugenics, as Blackwell does [140], citing a paper on eugenics from 1947. Logistic regression is a mathematical technique, possibly valuable, that is independent of any early uses of it [see Cramer 2010 or Simonoff 2003].)

Third, there is the problem of "oracles" and "ground truth" [141]. As Blackwell writes, "supervised learning" depends on humans having labeled data 
or outcomes, so that the machine has a defined goal. The sense of "supervised" is that the data are human-labeled, as if "...; item \#456, an outcome type "A"; item \#457, an outcome type "D"; ...". Such labeling can be very labor-intensive when the quantity of relevant data is huge, as it often is. Sometimes instead, an existing system or database can be used. In any of these cases, the reference to an "oracle" or to the "ground truth" points at the human-labeled "right answer". So here again, the subjectivity within the cyborg is actually composed from the subjective judgments of the humans who tagged the data or outcomes.

Last, but hardly least, there is McCarty's contribution [147-161]. McCarty by his subtitle- “Toward an Anthropology of the Artificially Intelligent"-grabs the cyborg by its uncanniness. The key insight here is that the cyborg requires a model, i.e., an ontology, of the domain to be affected [147]. Moreover, McCarty addresses the defamiliarization of the "person" via the creation of mechanical "persons", i.e., cyborgs, as well as how those types of persons relate to one another, and the key role of Wiener's approach to cybernetics in enabling the comparison [147-148]. That is, Wiener saw that something like a control system (feedback loop with a sensor to detect the difference between the actual state of the system and the desired state of the system) would be a good model for cyborgs as well as for humans [Wiener 1966]. Now McCarty asks readers to imagine a Turing-test-like conversation with an actual cyborg and announces that we would feel alienated, that we would find ourselves faced with the chasm of incommensurability [148-149]. He writes that the cyborg would be "enigmatically and unresolvably both like and unlike us". How, I ask, is that situation different from what we manage every day, talking with the aliens all around us? It may differ in degree but it is not different in kind. The "anthropology" in McCarty's title both foregrounds the problem to be faced in dealing with cyborgs and also indicates the response. Indeed, he concludes that machine intelligence is commensurable with ours, but that we should not underestimate the difficulty of communication [154-155]. McCarty argues [155-156] for a slow evolution of "bridgeheads" of mutual understanding [citing Lloyd 2010]. In the end, he says that to talk about cyborgs is to talk about "an emergent manifestation of ourselves differently constituted" [156].

Less convincing is McCarty's intervention on the "plurality of ontologies" within computer science [149-153]. Taking as his point of departure the observation that work on computers regularly creates a multiplicity of ontologies, McCarty argues that this plurality shows that "the ontological 
question was from the very beginning implicit in the design of the storedprogram computer" [150]. If the multiplicity of ontologies is intended to refer to the various object-hierarchies that constitute the structure of many programs, then this multiplicity would not be very meaningful. These object-hierarchies, which are also known as class hierarchies (with "class" here meaning something very like "category" or "type"), are created by the programmers ad hoc in order to organize their own thoughts and understandings about the program they are creating. Moreover, this mode of thought was not actually implicit in programs or computer architecture. Early programming languages, such as assembler, FORTRAN, ALGOL, or COBOL, had no notion of type-hierarchies. More recent languages include many that are constructed in terms of type-hierarchies; but even in those, the programmer can ignore that aspect of the language and write programs that do not reflect it at all. On the other hand, if the multiplicity of ontologies is intended to refer to the many object-hierarchies that organize the data being analyzed by the program, then again, this is not very meaningful. Such hierarchies are also ad hoc in that they are invented for the specific small set of problems being addressed in the current work of any given set of collaborating programmers. As McCarty says, such an ontology is "a practical inventory in a schema" [150]. One monistic attempt to create a hierarchy of everything has attracted adherents and criticism, namely, Cyc [https://www.cyc.com/], but has not yet produced any cyborgs.

\section{Conclusion}

Aliens of three kinds, then, have been encountered by the explorers whose reports grace the pages of this issue of $H A U$, a name that, as I understand it, refers to a gift. The volume is indeed freely available, and well worth taking the time to read. I encourage engaging and reflecting, and further reporting.

\section{BIBLIOGRAPHY}

Bacon, F. 1620. Instauratio Magna. London, UK.

Barton, B. 1996. "Anthropological Perspectives on Mathematics and Mathematics Education”. Pp. 1035-1053 in A. J. Bishop, K. Clements, C. Keitel, J. Kilpatrick, and C. Laborde edd. International Handbook of Mathematics Education. Dordrecht.

Boruchoff, D. A. 2012. "The Three Greatest Inventions of Modern Times: An Idea and Its Public". Pp. 133-163 in K. Hock and G. Mackenthun 
edd. Entangled Knowledge: Scientific Discourses and Cultural Difference. Munster.

Chahine, I. C. and N. Naresh. 2013. "Mapping the Cognitive Competencies of Street Vendors and Bus Conductors: A Cross-Cultural Study of Workplace Mathematics". Revista Latinoamericana de Etnomatemática 6: 7-35.

Chemla, K. 2013. "Ancient Writings, Modern Conceptions of Authorship: Reflections on Some Historical Processes that Shaped the Oldest Extant Mathematical Sources from Ancient China”. Pp. 63-82 in M. Asper ed. Writing Science: Medical and Mathematical Authorship in Ancient Greece. Berlin. https://dx.doi.org10.1515/9783110295122.63.

Chrisomalis, S. 2010. Numerical Notation: A Comparative History. Cambridge, UK.

Cramer, J. S. 2010. "The Origins and Development of the Logit Model”. Pp. 149-157 in J. S. Cramer ed. Logit Models from Economics and Other Fields. Cambridge, UK. https://dx.doi.org/10.1017/ CBO9780511615412.010.

Diels, H. and W. Kranz. 1951. Die Fragmente der Vorsokratiker. Griechisch und deutsch. 6th edn. Berlin.

Eisenhart, M. A. 1988. “The Ethnographic Research Tradition and Mathematics Education Research”. Journal for Research in Mathematics Education 19:99-114.

Goodson, L. and M. Vassar. 2011. "An Overview of Ethnography in Healthcare and Medical Education Research". Journal of Educational Evaluation for Health Professions 8.4. Unpaginated. https://dx.doi.org/10.3352/jeehp.2011.8.4.

Holmes, B. 2020. "At the End of the Line: On Kairological History". Classical Receptions Journal 12: 62-90. https://dx.doi.org/10.1093/crj/ clzo27.

Ilardi, V. 2007. Renaissance Vision from Spectacles to Telescopes. Philadelphia, PA.

Joralemon, D. 2017. Exploring Medical Anthropology. 4th edn. New York.

Keyser, P. T. 2010. "Science”. Pp. 859-881 in A. Barchiesi and

W. Scheidel edd. Oxford Handbook of Roman Studies. Oxford. https://dx.doi.org/10.1093/oxfordhb/9780199211524.013.0055.

Kidder, T. 1981. The Soul of a New Machine. Boston, MA. 
Laufer, B. 1907. "Zur Geschichte der Brille”. Mitteilungen zur Geschichte der Medizin und der Naturwissenschaften 6: 379-385.

Lloyd, G. E. R. 1987. Revolutions of Wisdom: Studies in the Claims and Practice of Ancient Greek Science. Berkeley, CA. 2002. Ambitions of Curiosity: Understanding the World in Ancient Greece and China. Cambridge, UK. 2010. "History and Human Nature: Cross-Cultural Universals and Cultural Relativities". Interdisciplinary Science Reviews 35: 201-214. https://dx.doi.org/10.1179/030801810X12723585301318. 2012. Being, Humanity, and Understanding: Studies in Ancient and Modern Societies. Oxford.

2015. Analogical Investigations: Historical and Cross-Cultural Perspectives on Human Reasoning. Cambridge, UK.

Lloyd, G. E. R. and A. Vilaça. 2019. edd. Special Issue: "Science in the Forest, Science in the Past". Hau: Journal of Ethnographic Theory 9.1. Chicago.

Michalowski, P. 2017. "Literary Journeys from Babylonia to Assyria: Second Millennium Copies of a Bilingual Poem Concerning Ninurta”. Pp. 205-230 in L. Feliu ed. The First Ninety Years: A Sumerian Celebration in Honor of Miguel Civil. Boston, MA/Leiden. https://dx.doi.org/10.1515/9781501503696-013.

Millroy, W. L. 1991. "An Ethnographic Study of the Mathematical Ideas of a Group of Carpenters". Learning and Individual Differences 3: 1-25.

Minnis, P. E. 2000. ed. Ethnobotany: A Reader. Norman, OK.

Needham, J. 1962. Science and Civilisation in China. vol. 4.1. Cambridge, UK.

Oppenheim, A. L. 1977. Ancient Mesopotamia: Portrait of a Dead Civilization. Chicago, IL

Pauling, L. 1960. The Nature of the Chemical Bond and the Structure of Molecules and Crystals. 3 rd edn. Ithaca, NY.

Pfeiffer, J. and M. Nichter. 2008. "What Can Critical Medical Anthropology Contribute to Global Health?” Medical Anthropology Quarterly ns $22: 410-415$.

Porzig, W. 1934. "Wesenhafte Bedeutungsbeziehungen”. Beiträge zur Geschichte der deutschen Sprache und Literatur 58: 70-97. 
Prance, G. T.; D. J. Chadwick; and J. Marsh. 1994. edd. Ethnobotany and the Search for New Drugs. Chichester, UK/New York.

Rivera, F. and J. Rossi Becker. 2008. "Ethnomathematics in the Global Episteme: Quo Vadis?” Pp. 209-225 in B. Atweh, A. C. Barton, M. C. Borba, N. Gough, C. Keitel, C. Vistro-Yu, and R. Vithal edd. Internationalisation and Globalisation in Mathematics and Science Education. Dordrecht.

Rosen, E. 1956. “The Invention of Eyeglasses”. Journal of the History of Medicine and Allied Sciences 11:13-46, 183-218.

Simonoff, J. S. 2003. Analyzing Categorical Data. New York.

Singer, M.; H. Baer; D. Long; and A. Pavlotski. 2020. Introducing Medical Anthropology: A Discipline in Action. 3rd edn. London, UK.

Soejarto, D. D.; H. H. S. Fong; G. T. Tan; H. J. Zhang; C. Y. Ma; S. G. Franzblau; C. Gyllenhaal; M. C. Riley; M. R. Kadushin; J. M. Pezzuto; L. T. Xuan; N. T. Hiep; N. V. Hung; B. M. Vu; P. K. Loc; L. X. Dac; L. T. Binh; N. Q. Chien; N. V Hai.; T Q. Bich; N. M. Cuong; B. Southavong; K. Sydara; S. Bouamanivong; H. M. Ly; T. Van Thuy; W. C. Rose; and G. R. Dietzman. 2005. "Ethnobotany/Ethnopharmacology and Mass Bioprospecting: Issues on Intellectual Property and Benefit-Sharing," Journal of Ethnopharmacology 100: 15-22. https://dx.doi.org/10.1016/j.jep.2005.05.031.

Sorabji, R. 1993. Animal Minds and Human Morals: The Origins of the Western Debate. Ithaca, NY.

Stillwell, J. 2016. Elements of Mathematics: From Euclid to Gödel. Princeton, NJ.

Traweek, S. 1988. Beamtimes and Lifetimes: The World of High Energy Physicists. Cambridge, MA.

Vithal, R. and O. Skovsmose. 1997. "The End of Innocence: A Critique of 'Ethnomathematics'”. Educational Studies in Mathematics 34: 131-157. https://dx.doi.org/10.1023/A:1002971922833.

Voeks, R. A. 2018. The Ethnobotany of Eden: Rethinking the Jungle Medicine Narrative. Chicago, IL.

Volkov, A. 2014. "Mathematics Education in East- and Southeast Asia". Pp. 55-72, 79-82 in A. Karp and G. Schubring edd. Handbook on the History of Mathematics Education. New York. https://dx.doi.org/10.1007/978-1-4614-9155-2_4.

Wiener, N. 1996. God and Golem, Inc.: A Comment on Certain Points Where Cybernetics Impinges on Religion. Cambridge, MA. 